\title{
Intraoperative radiofrequency ablation and distilled water peritoneal lavage for spontaneously ruptured hepatocellular carcinoma
}

\author{
Bong Jun Kwak', Joonseon Park', Yong Kyong Kwon², Jung Hyun Kwon³, Young Chul Yoon'1 \\ ${ }^{1}$ Division of Hepatobiliary, Pancreas, and Abdominal Organ Transplant, Department of Surgery, Incheon St. Mary's Hospital, \\ College of Medicine, The Catholic University of Korea, Incheon, Korea \\ ${ }^{2}$ Division of Hepatobiliary, Pancreas, and Abdominal Organ Transplant, Department of Surgery, Keck School of Medicine, \\ University of Southern California, Los Angeles, CA, USA \\ ${ }^{3}$ Division of Hepatology, Department of Internal Medicine, Incheon St. Mary's Hospital, College of Medicine, The Catholic \\ University of Korea, Seoul, Korea
}

Purpose: Spontaneously ruptured hepatocellular carcinoma (srHCC) is known to be a life-threatening complication with poor prognosis. Although there are various treatment modalities, there is no definite treatment guideline. The purpose of this study was to review the surgical outcome and prognosis of srHCC treated with intraoperative radiofrequency ablation (RFA) and distilled water peritoneal lavage (DWPL).

Methods: From March 2012 to October 2018, 9 patients with srHCC who underwent emergent surgery were reviewed. After hematoma removal, intraoperative RFA and DWPL were applied to all patients. Hepatectomy was performed if necessary. Patients with multiple tumors, distant metastasis, and vascular tumor involvement in radiologic imaging were excluded. Results: Six of 9 patients with diameters less than $7 \mathrm{~cm}$ were able to obtain hemostasis using RFA alone (RFA group). However, 3 patients with a tumor size of more than $10 \mathrm{~cm}$ underwent liver resection because they could not obtain hemostasis with RFA (hepatectomy only group). The RFA group had shorter operation time $(148.3 \pm 31.7$ minutes vs. $251.7 \pm 20.2$ minutes, $P<0.05$ ) and less red blood cell transfusion $(5.8 \pm 2.5$ packs vs. $24.0 \pm 11.5$ packs, $P<0.05$ ) than the hepatectomy only group. There was no peritoneal metastasis at long-term follow-up in the RFA group. Five-year recurrence-free survival rate was $0 \%$ in both groups. However, 5 -year overall survival rate was better in the RFA group (83.3\% vs. $0 \%, \mathrm{P}<0.05)$.

Conclusion: Intraoperative RFA and DWPL are easy to perform and theoretically the best methods for managing relatively small srHCC.

[Ann Surg Treat Res 2019;97(6):291-295]

Key Words: Hepatocellular carcinoma, Peritoneal lavage, Prognosis, Radiofrequency ablation, Rupture

\section{INTRODUCTION}

With the development of various diagnostic tools and treat- ment modalities for hepatocellular carcinoma (HCC), more accurate diagnosis and guideline-based treatment have become possible. However, there is no definite treatment guideline
Received July 12, 2019, Revised October 6, 2019,

Accepted October 23, 2019

Corresponding Author: Young Chul Yoon

Division of Hepatobiliary, Pancreas, and Abdominal Organ Transplant,

Department of Surgery, Incheon St. Mary's Hospital, College of Medicine,

The Catholic University of Korea, 56 Dongsu-ro, Bupyeong-gu, Incheon

21431, Korea

Tel: +82-32-280-5862, Fax: +82-32-280-5988

E-mail: k07yyc@catholic.ac.kr

ORCID: https://orcid.org/0000-0002-5341-2370
Copyright (c) 2019, the Korean Surgical Society

(c) Annals of Surgical Treatment and Research is an Open Access Journal. All articles are distributed under the terms of the Creative Commons Attribution NonCommercial License (http://creativecommons.org/licenses/by-nc/4.0/) which permits unrestricted non-commercial use, distribution, and reproduction in any medium, provided the original work is properly cited. 
for spontaneously ruptured HCC (srHCC). It is because the situation of srHCC is diverse, making it difficult to collect enough data to perform large scale research. The initial goal of srHCC treatment is to establish hemodynamic stability and maintain liver function. Surgery and transarterial embolization (TAE) are the most commonly used methods for hemostasis. Compared to surgery, TAE is easy to perform with lower 30day mortality (0\%-37\% vs. $28 \%-75 \%$ ) [1]. To achieve longterm survival after performing TAE, definite treatment such as surgical resection is required. Surgery for srHCC can be divided into interventions for hemostasis and hepatectomy for definite treatment. Interventions for surgical hemostasis include perihepatic gauze packing, suture plication, and hepatic artery ligation [1]. If the patient is hemodynamically stable, one stage emergency liver resection is available. Otherwise, hemostasis is performed and staged liver resection is planned because liver resection is a burden on the patient. Radiofrequency ablation (RFA) is a definite treatment modality of HCC. It is frequently used as a percutaneous approach. In the management of srHCC, intraoperative RFA allows hemostasis and complete tumor necrosis [2-4]. From the patient and surgeon's standpoint, intraoperative RFA is less burdensome and easier than liver resection when treating srHCC. The greatest advantage of surgery including intraoperative RFA in the management of srHCC is its ability to manage peritoneal tumor seedings definitely. Distilled water peritoneal lavage (DWPL) can effectively remove peritoneal tumor seedings in srHCC patients [5-7]. Here, we report the result after application of intraoperative RFA and DWPL to srHCC patients.

\section{METHODS}

\section{Patients}

From March 1, 2012 to October 31, 2018, 9 patients who underwent surgery among patients who visited the emergency room with srHCC were retrospectively studied. All patients were checked with contrast-enhanced abdominal CT and chest X-ray. When hemodynamically stable, we conducted a chest CT. Patients with multiple tumors, distant metastasis, and vascular tumor involvement in radiologic imaging were excluded from the surgery. Preoperative Child-Pugh score, tumor diameter, operation time, and amount of red blood cell transfusion were measured for all patients. However, data of tumor markers were not available for all patients in urgent situations. Postoperative surveillance was done with contrast-enhanced chest-abdomen CT every 3 months and 6 months intervals after 1 year. This study was approved by the Institutional Review Board (IRB) of Catholic University Incheon St. Mary's Hospital (approval number: OC19RESI0067) and exempt from informed consent by IRB approval.

\section{Surgical technique}

After making the patient hemodynamically stable, hematoma was removed by laparotomy and hemostasis was achieved with gauze packing. Liver mobilization was minimized to prevent tumor seeding. RFA electrode was directly applied to the tumor in the gauze packing state (Fig. 1). In the gauze packing state, there was no tumor seeding by the RFA. The power generator output was set to $120 \mathrm{~W}$ from the beginning and the temperature of the electrode was set to $100^{\circ} \mathrm{C}$. The electric pulse-type was set to be continuance type. All patients were ablated for more than 10 minutes to obtain hemostasis. If hemostasis was not obtained, the procedure was repeated. When the bleeding stopped, we used ultrasonography to check that the ablation was sufficient. Ablation was repeated if necessary. However, if hemostasis was not obtained despite repeated ablation, we performed liver resection. After managing the HCC in liver, DWPL was performed for more than 15 minutes using $10 \mathrm{~L}$ of distilled water at $35^{\circ} \mathrm{C}-40^{\circ} \mathrm{C}$ as previously reported $[7,8]$.

\section{Statistical analysis}

A comparison between groups was performed using a MannWhitney U-test for nonparametric continuous variables and chisquare test for categorical variables. Overall and recurrencefree survival were calculated using the Kaplan-Meier method. Survival differences between groups were assessed using the log-rank test. All statistical analyses were conducted using IBM SPSS Statistics ver. 24.0 (IBM Co., Armonk, NY, USA). A statistical significance was considered at P-value $<0.05$.

\section{RESULTS}

\section{Baseline characteristics of patients and surgical outcomes \\ All 9 patients were hepatitis B related. Their main symptoms}

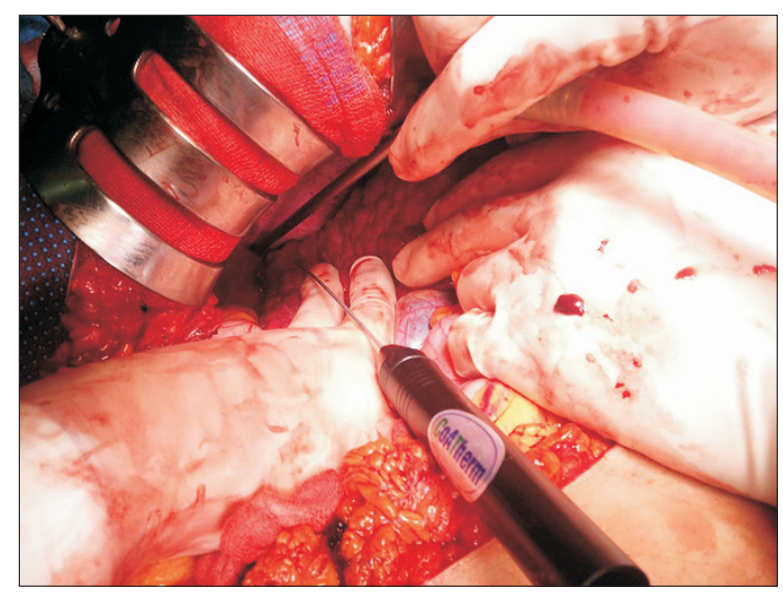

Fig. 1. Intraoperative findings of a patient who underwent radiofrequency ablation after hematoma removal. 
at the emergency room were syncope for 5 patients, abdominal pain and distension for 3 patients, and right shoulder pain for 1 patient. All patients were diagnosed with srHCC on contrast-enhanced abdominal CT. All patients were transferred to the operating room within 4 hours after arrival at the emergency room. We attempted hemostasis using RFA for all 9 patients. However, only 6 patients whose tumor diameter within $7 \mathrm{~cm}$ achieved hemostasis with RFA (RFA group). The remaining 3 patients who had tumors larger than $10 \mathrm{~cm}$ could not achieve hemostasis using RFA alone. They underwent liver resection (hepatectomy only group). In the RFA group, 2 patients whose tumor was located in segment 3 underwent left lateral sectionectomy sequentially because the tumor was too close to the glissonean pedicle based on ultrasonography. In the hepatectomy only group, 1 patient underwent nonanatomical tumorectomy and the other 2 underwent right hemihepatectomy. After RFA or hepatectomy, all patients underwent DWPL for 15-20 minutes (Table 1). The mean age of the RFA group was $59.3 \pm 8.0$ years. There were 4 males $(66.7 \%)$ in the RFA group. For the RFA group, mean Child-Pugh score of $5.3 \pm 0.5$, average tumor diameter of $4.4 \pm 2.0 \mathrm{~cm}$ (range,

Table 2. Patient characteristics of successful versus failed radiofrequency ablation

\begin{tabular}{lccc}
\hline \multicolumn{1}{c}{ Characteristic } & $\begin{array}{c}\text { RFA group } \\
(\mathrm{n}=6)\end{array}$ & $\begin{array}{c}\text { Hepatectomy } \\
\text { only group } \\
(\mathrm{n}=3)\end{array}$ & P-value \\
\hline Age (yr) & $59.3 \pm 8.0$ & $70.7 \pm 9.2$ & 0.068 \\
Sex, male:female & $4: 2$ & $3: 0$ & 0.316 \\
Child score & $5.3 \pm 0.5$ & $5.0 \pm 0.0$ & 0.285 \\
Tumor size (cm) & $4.4 \pm 2.0$ & $12.3 \pm 2.5$ & $<0.05$ \\
Operation time (min) & $148.3 \pm 31.7$ & $251.7 \pm 20.2$ & $<0.05$ \\
RBC transfusion (pack) & $5.8 \pm 2.5$ & $24.0 \pm 11.5$ & $<0.05$ \\
In hospital mortality (\%) & 0 & 33.3 & 0.170
\end{tabular}

Values are presented as mean \pm standard deviation or number. RFA, radiofrequency ablation; RBC, red blood cell.

Table 1. Background features of patients who underwent surgery for spontaneously ruptured hepatocellular carcinoma

\begin{tabular}{|c|c|c|c|c|c|c|}
\hline Patient No. & Sex/age (yr) & $\begin{array}{l}\text { Maximum tumor } \\
\text { diameter }(\mathrm{cm})\end{array}$ & $\begin{array}{l}\text { Involved } \\
\text { segment }\end{array}$ & Operation method & $\begin{array}{l}\text { Operation time } \\
\text { (min) }\end{array}$ & $\begin{array}{l}\text { In hospital } \\
\text { mortality }\end{array}$ \\
\hline 1 & $M / 59$ & 2.0 & 1 & $\mathrm{RFA}+\mathrm{DWPL}$ & 120 & No \\
\hline 2 & $\mathrm{~F} / 70$ & 3.0 & 7 & $R F A+D W P L$ & 135 & No \\
\hline 3 & $M / 66$ & 4.0 & 4 & $\mathrm{RFA}+\mathrm{DWPL}$ & 180 & No \\
\hline 4 & $\mathrm{~F} / 57$ & 4.0 & 8 & $\mathrm{RFA}+\mathrm{DWPL}$ & 120 & No \\
\hline 5 & $M / 47$ & 6.5 & 3 & RFA + LLS + DWPL & 140 & No \\
\hline 6 & $M / 57$ & 7.0 & 3 & $\mathrm{RFA}+\mathrm{LLS}+\mathrm{DWPL}$ & 195 & No \\
\hline 7 & $M / 76$ & 10.0 & 7 & Tumorectomy + DWPL & 240 & Yes \\
\hline 8 & $M / 76$ & 12.0 & 7,8 & $\mathrm{RH}+\mathrm{DWPL}$ & 275 & No \\
\hline 9 & $M / 60$ & 15.0 & 7,8 & $\mathrm{RH}+\mathrm{DWPL}$ & 240 & No \\
\hline
\end{tabular}

RFA, radiofrequency ablation; DWPL, distilled water peritoneal lavage; LLS, left lateral sectionectomy; $\mathrm{RH}$, right hemihepatectomy.

A

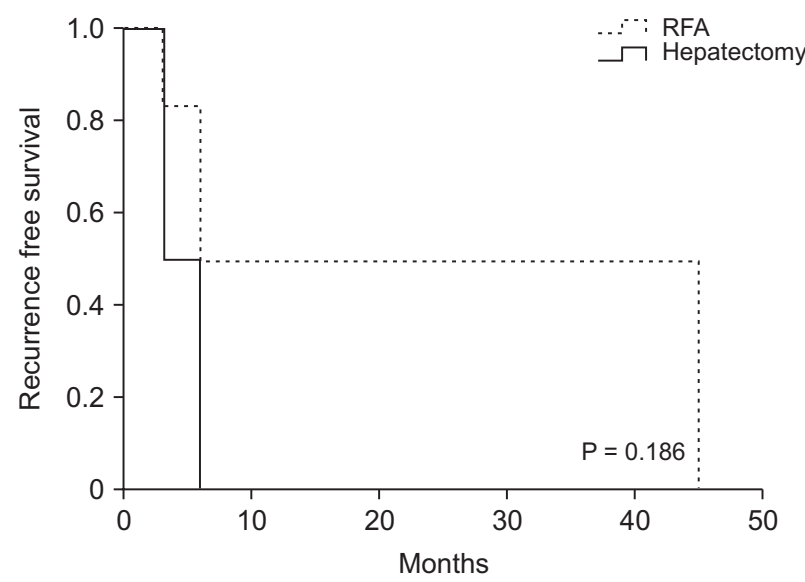

B

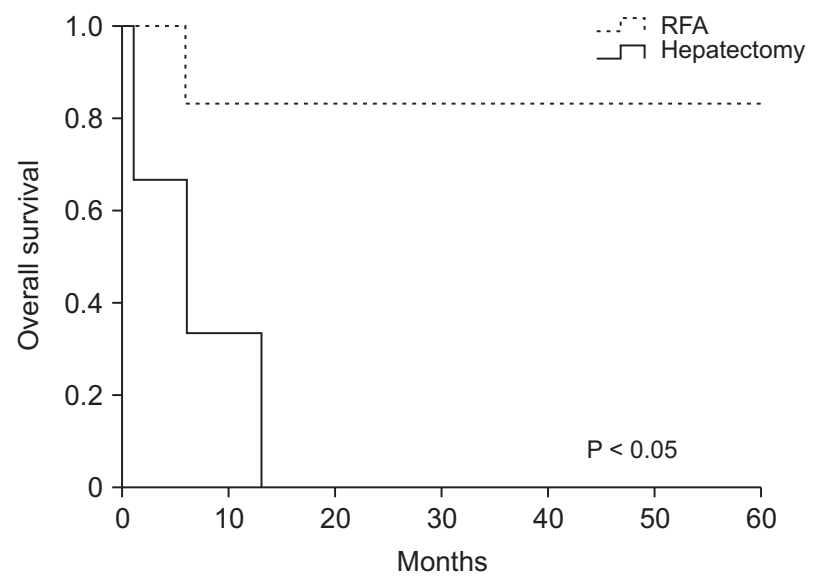

Fig. 2. Cumulative recurrence-free survival (A) and overall survival (B) after spontaneous ruptured hepatocellular carcinoma in the radiofrequency ablation (RFA) and hepatectomy only groups. There was no significant difference in recurrence-free survival between these 2 groups $(P=0.186)$. However, there were significant differences in overall survival between these 2 groups $(P<$ 0.05). 
2-7 cm), mean operation time of $148.3 \pm 31.7$ minutes, RBC transfusion of $5.8 \pm 2.5$ packs (range, 2-9 packs) were found. There was no immediate postoperative mortality in the RFA group. The mean age of the hepatectomy only group was $70.7 \pm$ 9.2 years. All patients were men. Mean Child-Pugh score of 5.0 \pm 0.0 , average tumor diameter of $12.3 \pm 2.5 \mathrm{~cm}$ (range, 10-15 $\mathrm{cm})$, mean operation time of $251.7 \pm 20.2$ minutes, and mean RBC transfusion of $24.0 \pm 11.5$ packs (range, 15-37 packs) were found for this group. One patient died of posthepatectomy liver failure (Table 2).

\section{Long-term outcomes}

Four patients in the RFA group had recurrent HCC. Three of them recurred in the liver and the other was diagnosed with lung metastasis. However, there was no peritoneal metastasis. The 5-year survival of the RFA group was $83.3 \%$. All patients in the hepatectomy only group had multiple liver recurrence during the follow-up period and 1 patient had peritoneal metastasis despite DWPL. All patients in the hepatectomy only group died within 13 months (Fig. 2).

\section{DISCUSSION}

Until the early 2000s, acute phase mortality of srHCC was as high as $25 \%$ to $75 \%[1,9]$. The reason for such a result was that surgery was applied as an initial treatment to patients with srHCC. The survival rate was improved by selecting TAE as the initial treatment. Staged liver resection after TAE showed better long-term survival rate (1-year survival, $54.2 \%-100 \%$; 3-year survival, 21.2\%-48\%; 5-year survival, 15-21.2\%) [1]. Most centers currently use this method. However, it remains unclear whether this is the best method. Even in the European Association for the Study of the Liver and the European Organization for Research and Treatment of Cancer clinical practice guideline, the American Association for the Study of Liver Diseases guideline, and the Korean Liver Cancer Association guideline for HCC treatment, there is no definite treatment guideline for srHCC [10-12]. The problem in TAE with initial treatment and subsequently staged hepatectomy is that it cannot completely prevent peritoneal tumor seedings. TAE is a good method to stop bleeding in the acute phase with a high success rate of $53 \%-100 \%[1,13-16]$. However, if hemostasis cannot be achieved by TAE, emergent surgical intervention is needed. In addition, it is hard to manage abdominal distension and infection caused by hemoperitoneum. Hepatic failure by TAE has also been reported in $12 \%-34 \%$ of cases $[1,16,17]$. In the management of srHCC, intraoperative RFA can be an alternative to liver resection because it can obtain hemostasis and direct tumor necrosis [2-4]. RFA is easier than liver resection. It has a relatively low burden on patients and surgeons. To prevent peritoneal tumor seeding, DWPL after srHCC should be performed as soon as possible. Our center decided to perform intraoperative RFA and DWPL to patients who were Child-Pugh classification A, single HCC, no distant metastasis, and no vascular tumor involvement on radiologic imaging after a multidisciplinary consensus meeting. Intraoperatively, compression of the tumor mass with gauze made hemostasis easy using RFA when the tumor size was less than $7 \mathrm{~cm}$. However, if the tumor diameter was more than 10 $\mathrm{cm}$, hemostasis was not possible even with several times of ablation for every 10 minutes. In addition, tumor spillage was further increased by several ablations. We have used a straight single type RFA electrode. If we used another electrode later, for example, multitined radiofrequency electrode, it might be possible to ablate larger diameter HCC. The 5-year survival rate of the RFA group was $83.3 \%$. It was similar to that of nonruptured HCC. Because all our patients with srHCC were nodular type HCC, presumably their survival rate was not worse. In addition, since srHCC usually occurs in nodule type $\mathrm{HCC}$, the prognosis is not worse than that of the same size HCC when the treatment method is well selected. All patients in the hepatectomy only group had a worse prognosis. They all died within 13 months. This result was similar to those of other studies $[1,18]$. Therefore, until the development of an electrode capable of ablation of a larger diameter srHCC, we think that a staged hepatectomy after emergent TAE is reasonable for a srHCC of larger than $10 \mathrm{~cm}$.

In conclusion, intraoperative RFA and DWPL might be an ideal treatment for managing relatively small size srHCC, although we cannot confirm this because only a limited number of patients were enrolled in this study.

\section{CONFLICTS OF INTEREST}

No potential conflict of interest relevant to this article was reported.

\section{REFERENCES}

1. Lai EC, Lau WY. Spontaneous rupture of hepatocellular carcinoma: a systematic review. Arch Surg 2006;141:191-8.

2. Ng KK, Lam CM, Poon RT, Law WL, Seto
CL, Fan ST. Radiofrequency ablation as a salvage procedure for ruptured hepato- 
cellular carcinoma. Hepatogastroenterology 2003:50:1641-3.

3. Fuchizaki U, Miyamori H, Kitagawa S, Kaneko S. Radiofrequency ablation for life-threatening ruptured hepatocellular carcinoma. J Hepatol 2004:40:354-5.

4. Sun WB, Ding XM, Ke S, Gao J, Zhang YF. Repeated radiofrequency ablation as both salvage solution and curative treatment for spontaneous rupture of giant medial lobe hepatocellular carcinoma. Chin Med J (Engl) 2009;122:2067-70.

5. Chang YM, Hsu KF, Yu JC, Chan DC, Chen CJ, Chen TW, et al. Distilled water peritoneal lavage in patients with rupture hepatocellular carcinoma. Hepatogastroenterology 2013;60:140-3.

6. Zhou SJ, Zhang EL, Liang BY, Zhang ZY, Chen XP, Huang ZY. Distilled water lavage during surgery improves long-term outcomes of patients with ruptured hepatocellular carcinoma. J Gastrointest Surg 2015;19:1262-70.

7. Lin CH, Hsieh HF, Yu JC, Chen TW, Yu CY, Hsieh CB. Peritoneal lavage with distilled water during liver resection in patients with spontaneously ruptured hepatocellular carcinomas. J Surg Oncol 2006;94: 255-6.
8. Huguet EL, Keeling NJ. Distilled water peritoneal lavage after colorectal cancer surgery. Dis Colon Rectum 2004:47:21149.

9. Tanaka A, Takeda R, Mukaihara S, Hayakawa K, Shibata T, Itoh K, et al. Treatment of ruptured hepatocellular carcinoma. Int J Clin Oncol 2001;6:291-5.

10. European Association for the Study of the Liver; European Organisation for Research and Treatment of Cancer. EASL-EORTC clinical practice guidelines: management of hepatocellular carcinoma. J Hepatol 2012;56:908-43.

11. Heimbach JK, Kulik LM, Finn RS, Sirlin CB, Abecassis MM, Roberts LR, et al. AASLD guidelines for the treatment of hepatocellular carcinoma. Hepatology 2018;67:358-80.

12. Korean Liver Cancer Association; National Cancer Center. 2018 Korean Liver Cancer Association-National Cancer Center Korea Practice Guidelines for the management of hepatocellular carcinoma. Gut Liver 2019;13:227-99.

13. Yoshida H, Mamada Y, Taniai N, Uchida E. Spontaneous ruptured hepatocellular carcinoma. Hepatol Res 2016;46:13-21.

14. Kung CT, Liu BM, Ng SH, Lee TY, Cheng
YF, Chen MC, et al. Transcatheter arterial embolization in the emergency department for hemodynamic instability due to ruptured hepatocellular carcinoma: analysis of 167 cases. AJR Am J Roentgenol 2008;191:W231-9.

15. Jin YJ, Lee JW, Park SW, Lee JI, Lee DH, Kim YS, et al. Survival outcome of patients with spontaneously ruptured hepatocellular carcinoma treated surgically or by transarterial embolization. World J Gastroenterol 2013;19:4537-44.

16. Liu CL, Fan ST, Lo CM, Tso WK, Poon RT, Lam CM, et al. Management of spontaneous rupture of hepatocellular carcinoma: single-center experience. J Clin Oncol 2001;19:3725-32.

17. Ngan H, Tso WK, Lai CL, Fan ST. The role of hepatic arterial embolization in the treatment of spontaneous rupture of hepatocellular carcinoma. Clin Radiol 1998:53:338-41.

18. Sahu SK, Chawla YK, Dhiman RK, Singh V, Duseja A, Taneja S, et al. Rupture of hepatocellular carcinoma: a review of literature. J Clin Exp Hepatol 2019;9:24556. 